trachomatis and $N$ gonorrhoea cervicitis in pregnancy. Genitourin Med 1990;66:62-65.

6 Au-Ping N, Chun-Xia G, Shi-Tai L, et al. The prevalence of Chlamydia infection in outpatient clinics in Beijing, China. Genitourin Med 1990;66:125.

Accepted for publication 12 January 1993.

\section{Prevalence and awareness of hepatitis B virus carrier status in Italy}

Knowledge of hepatitis $B$ surface antigen (HBsAg) status is the first and easiest preventive measure for reducing diffusion of hepatitis B virus (HBV) in sexual partners, family members and, more in general, in the community. To assess the extent of knowledge of $\mathrm{HBsAg}$ status in an Italian population, we have reanalysed data for subjects interviewed as controls in a case-control study of risk factors for lichen planus conducted in northern Italy between 1989 and $1990 . .^{1}$ A total of 1031 subjects ( 529 men, 502 women, median age 47 years, range $16-88$ years) were interviewed in the outpatient services of participating centres for dermatological conditions other than lichen planus (such as pityriasis rosea, urticaria, psoriasis, neoplastic skin diseases, exanthemas, skin infections, burns). Subjects were not included if they had cutaneous diseases associated with liver dysfunction. Ten of the 1031 subjects $(1 \cdot 0 \%)$ declared at the interview that they were HBSAg positive. At the time of the interview, a serum sample was also taken. Based on serological determinations, 27 subjects $(2 \cdot 7$ $\%)$, including the 10 patients who reported $\mathrm{HBsAg}$ positivity, were HBSAg carriers. Although our controls are not a representative sample of the Italian population, they are probably a sample not biased toward a lower than average attention to health problems. As a consequence, our results suggest that a large proportion of Italian HBSAg carriers are unaware of their condition.

The estimated prevalence of $\mathrm{HBsAg}$ carriers in Italy lies between $2 \%$ and $4 \%(2-3)$; and, based on our results, 1.2-2.5 \% of Italian people (about 700 000-1 400000 subjects) may be unaware of their $\mathrm{HBsAg}$ carrier status, with obvious consequences in terms of public health, that is, diffusion of HBV infection.

ALDO BREVI TULLIO CANNELLI Department of Dermatology, University of Milan, Bergamo General Hospital, Italy FABIO PARAZZINI Institute for Pharmacological Research "Mario Negri", Milan, Italy (Italian Group for Epidemiologic Research in Dermatology)

Address correspondence to: Dr Luigi Naldi, Cattedra di Clinica Dermosifilopatica, Università degli studi di Milano, Ospedali Riuniti-largo Barozzi, 1, 24100 Bergamo, Italy.

1 Gruppo Italiano Studi Epidemiologici in Dermatologia (GISED). Lichen planus and liver diseases: a multicentre case-control study. BMЯ 1990;300:227-30

2 Pasquini P, Kahn HA, Pileggi D, Panà A, Terzi J, Guzzanti E. Prevalence of hepatitis B markers in Italy. Am f Epidemiol 1983;118:699-709.

3 Dardanoni L, Mele A, Polizzi MC. Epidemiology of hepatitis B in Italy. Ann 1st Super Sanità 1988;24: 235-244.
In vitro susceptibility of Trichomonas vaginalis strains to metronidazole-a Nigerian experience

Recent reports have indicated the prevalence of cases of refractory vaginal trichomoniasis associated with isolates that were resistant to metronidazole. ${ }^{3-5}$

We have tested the in vitro susceptibility to metronidazole of 41 freshly isolated local strains of Trichomonas vaginalis at Jos University Teaching Hospital, Nigeria to determine the possible emergence of resistant strains in our locality. The strains were isolated using the trichomonas medium as modified by Adebayo, 1988. The minimum inhibitory concentrations (M.I.C.) of metronidazole to the isolated strains were determined using the disc broth method of Smith and DiDomenico. ${ }^{7}$

The minimum inhibitory concentration ranged from less than $0.03 \mathrm{mcg} / \mathrm{ml}$ to $2 \cdot 0$ $\mathrm{mcg} / \mathrm{ml}$, using $10^{5}$ organisms per millimetre inoculum size and at 2 days incubation period. Thirty strains $(73 \cdot 17 \%)$ had M.I.C. of less than $0.03 \mathrm{mcg} / \mathrm{ml}$, while only $3(7.32 \%)$ had the highest prevalent M.I.C. of $2 \cdot 0$ $\mathrm{mcg} / \mathrm{ml}$ (see table)

Table Activity in vitro of metronidazole against $T$ Vaginalis (minimum inhibitory concentration)

\begin{tabular}{llc}
\hline M.I.C. $(\mathrm{Mcg} / \mathrm{ml})$ & $\begin{array}{l}\text { Number of sensitive } \\
\text { strains }\end{array}$ & $\%$ Sensitivity \\
\hline$<0.03$ & 30 & $73 \cdot 17$ \\
0.06 & 3 & $7 \cdot 32$ \\
0.25 & 1 & $2 \cdot 43$ \\
0.50 & 2 & $4 \cdot 88$ \\
1.0 & 2 & $4 \cdot 88$ \\
$2 \cdot 0$ & 3 & $7 \cdot 32$ \\
Total & 41 & 100 \\
\hline
\end{tabular}

It is therefore concluded that the Trichomonas vaginalis strains in our locality are still very sensitive to metronidazole, and any treatment failures may be due to noncompliance and re-infection on the part of the patients. Also the cure of vaginal trichomoniasis does not simply have a direct relationship between susceptibility of the organism and drug dosage, but probably depends on a complex interaction of several factors including drug susceptibility, intra-vaginal redox potential which may regulate the amount of drug taken up by the parasite ${ }^{5}$ and the accompanying vaginal microflora which may modify the amount of available drug in situ. ${ }^{2}$

E I IKEH C S S BELLO Department of Medical Microbiology, Faculty of Medical Sciences, University of fos, PMB 2084, fos, Plateau State, Nigeria J A AJAYI

Department of Zoology, University of fos, Nigeria

1 Adebayo JA. Isolation of Trichomonas vaginalis: A simple diagnostic medium for use in developing countries. Med Lab Scis. 1988;45:273-4.

2 Edwards DI, Thompson EJ, Tomusange J, Shanson D. Inactivation of Metronidazole by aerobic organisms. $\dot{f}$ Antimicrob Chemother. 1979;5:315-6.

3 Forsgren A, Forssman L. Metronidazole resistant Trichomonas vaginalis $B r \mathcal{F}$ Venereal Dis 1979;55:351-3.

4 Meingassner JG, Thurner J. Strain of Trichomonas vaginalis resistant to metronidazole. Antimicrob Agents Chemother. 1979;15:254-7.

5 Muller M, Lindmark DG. Uptake of metronidazole and its effect on viability in trichomonads and Entamoeba 